\title{
CHALLENGE-STRESS AND HINDRANCE-STRESS IN THE SOUTHEAST ASIAN HOTEL SECTOR
}

\author{
Kamaazura Abu Bakar \\ IKIP International College \\ (kamaazura@ikip.edu.my) \\ Ahmad Munir Mohd Salleh \\ Universiti Malaysia Terengganu \\ (munir_salleh@umt.edu.my) \\ Mohd Shaladdin Muda \\ Universiti Malaysia Terengganu \\ (shaladdin@umt.edu.my) \\ Azlinzuraini Ahmad \\ Universiti Malaysia Terengganu \\ ( azlinzuraini@umt.edu.my) \\ Ruzita Manshor \\ Kolej Antarabangsa IKIP \\ (ruzita_manshor@ikip.edu.my)
}

\begin{abstract}
The hospitality industry is an entity that is continuously determined by varying new demands and the needs of its customers. This ever-changing and complex working environment has caused and become a source of stress for the hospitality industries' workforce. Workplace stress is increasing from year to year and has become a focus of research interest in recent years. Responding to the demands of management who require a more precise understanding of the issues of workplace stress, researchers have conducted studies on a total of 115 respondents from a 3 star-hotel and a 4 star-hotel. The personnel involved came from the food and beverage departments, room services and the front offices, whose daily routines involved direct face to face serving activities and fulfilling their customers' demands. Using the Statistical Package for Social Science (SPSS) version 19.0 and AMOS version 18.0, the results of Exploratory Data Analysis (EFA) and Confirmatory Data Analysis (CFA) have confirmed that there are two stress factors, namely challenge stress and hindrance stress. Both of these stress factors have a significantly negative relation to one another. Understanding these dimensions in detail can help the hospitality organizations to be well prepared for the task of motivating their employees.
\end{abstract}

Keywords: challenge-stress, hindrance-stress, service, Southeast Asia, hotel

\section{INTRODUCTION}

Southeast Asia is among the regions in Asia that drastically increased their tourism industry with a 9.9 percent growth in tourist arrivals in the year 2013, and further growth is expected in 2014. Malaysia and Indonesia were among the Southeast Asian members that received higher tourist numbers, which are also expected to grow from year to year (The Jakarta Globe, 2013; World Travel and Tourism Council, 2014). In order to ensure the sustainability of this sector, stress issues have become a continuous fenomena that need to be highlighted in this industry. Workplace stress is an issue that causes boredom 
and dissatisfaction among employees (Poon, 2003; Blaug, Kenyon, \& Lehi, 2007; Srikhum, 2013).

Cooper \& Cartwright (1994) explained that stress at work will also lead to increased financial costs in business and industry (O'Neill \& Davis, 2011; Cooper \& Cartwright, 1994). Among the possible economic costs that will burden the industry are an increase in staff medical expenses, low morale and a lack of commitment among workers (Management Service, 2006). According to Steers \& Rhodes (1978) cited by Ivancevich (1985), the total annual cost of absenteeism from work in the United States was in the order of USD8.5 to USD26 billion. The costs incurred as a result of stress in the workplace were expected to increase from year to year. The United Kingdom also reported that the cost of absenteeism in that country was between $£ 10$ and $£ 12$ billion a year, averaging to a value of $£ 434$ per employee (Management Service, 2006). Therefore, the need to reduce stress is very vital to the longterm survival of the hospitality industries as stress may increase their operational costs. The potential loss of profit is very high if these work related stresses are not confined by prudent management strategies.

In the hospitality industry, frontline staff are highly vulnerable to stress. They are the group of workers that are directly involved with 'customer-oriented work' which means that their positions demand constant interaction with both parties i.e. the customer and the organization (Dewettinck \& Buyens, 2005: 422). Stress is said to be a reaction to weak individual capabilities and the work environment. Stress will manifest itself when the required task is beyond the capability of an individual, or the individual concerned does not have the right tools to handle the job situation (Jamal \& Baba, 2000). Jamal \& Baba (2000) also defined job stress as a natural consequence of human interaction with their work environment or situations that threaten them. This definition by Jamal \& Baba has been further refined by Greenberg (2005), who said that stress was an emotional and physiological reaction that occurred in response to the impact of internal and external demands of the work environment (Greenberg, 2005). However, the said impact will not be the same for one individual compared to another, because stress is a dynamic phenomenon. Individuals who experience stress will be confronted with opportunities, necessities and resources related to their individual intention, but the results are not conclusive (Robbins \& Judge, 2007).

\section{STRESS IN SERVICE}

According to Greenberg (2005), human service occupations will face high levels of stress and be susceptible to emotional exhaustion, such as in a situation where employees feel depressed and powerless. In the hotel sector, emotional exhaustion is influenced by various factors including facial expression procedures that must be followed. According to Samad (2009) and Aziz (2008), employees must smile for hours on end in serving the needs of customers.

However, stress does not necessarily prevail only in a negative form, but it is also present in a positive form (Robbins \& Judge, 2007). Based on Tuten \& Neidermeyer (2004), a moderate amount of stress will benefit employees and the organization. This beneficial stress is known as positive stress or as challenge stress. It will actually provoke the employees' self-esteem to a point where they will feel the need to excel in their working environment. Stress is beneficial when it is within the acceptance and competence of each individual employee, but it will turn unproductive when the stress level is too high and beyond the optimum stress limit that can be handled by the employees.

The negative stress or hindrance stress is more focused on the negative aspects of stress that prevents workers from reaching their goal. The examples of hindrance stress include organizational politics, inflexible bureaucracy, job demands, and job ambiguity, excessive anxiety and frustration (Robbins \& Judge, 2007; Cavanaugh et al., 1998, Cavanaugh et al., 2000). Hindrance stress will exist and employees will demonstrate poor performance (Hellriegel \& Slocum, 2004: 121; Robbins \& Judge, 2007: 
339). But this condition will only appear when the working environment received aggregate stress levels that exceed the tolerance level. This will lead to job dissatisfaction, depression and anger among the workers (Cavanaugh et al. 2000; Greenglass, Burke, \& Moore, 2003).

Due to the working environment, the hospitality industries' workers are customarily burdened with various difficulties in regard to the hindrance stress. This statement is supported by Karatepe \& Sokmen (2006) who said hotel workers were often faced with a conflict of roles and role ambiguity leading to hindrance stress. When there was no proper written procedure, employees often felt reluctant to react to various customers' complaints and this would eventually make the employees feel uncertain of how to interact with their customers (Dewettinck \& Buyens, 2005: 423).

Doing monotonous day-to-day tasks is considered the normal, essential routine in the service industry. For example, the method for how to greet customers has not changed at all over time. The recurrence of the same tasks will make employees feel displeased with their work. This conclusion was supported by Hoynala (2009) and Mullins (2005), who stated that repeating the same job every day without any variety in the work activities would create "worn-out" workers. A large number of customers all wanting to be served at the same time will also create a dilemma as it will put excessive constraints on the skills and abilities of the employees (Dewettinck \& Buyens, 2005: 422). A lack of autonomy in work situations will also add to the existing stress levels. All these shortfalls are explicit examples of hindrance stress.

According to Johnson \& Woods (2008), hospitality workers also performed various tasks like managing the diversity of client needs and office management. On occasions, they are required to perform these unrelated tasks in a very limited time frame and without adequate training. This will also contributed to the hindrance stress among workers (Mullins, 2005; Karatepe \& Kilic, 2007; Karatepe \& Uludag, 2008; Dean \& Rainnie, 2004).
Training is a critical factor to fortify employees' work aptitudes because it can improve their customer interaction competence and enhance their ability to manage routine tasks. Work simulation training can cultivate a more positive employee attitude when confronted with a stressful situation (Dean \& Rainnie, 2004; Karatepe, Babakus, \& Yavas, 2012). Simultaneously, employees also need to find a balance between work and family, even though most of their time is spent at work (Karatepe \& Kilic, 2007; Karatepe \& Sökmen, 2006). It would be prudent to consider that employees who experience hindrance stress will eventually contribute to achieving less than normal (Stevens \& Higgins 2002). This situation will certainly weaken the customer service orientation and further undermine the sustainability of the organization in the highly competitive hospitality industry.

\section{STRESS IMPACT IN HOSPITALITY INDUSTRY}

Too much stress is injurious to the individual and institution involved. However, if the root cause of the stress can be dealt with, in accordance with the different ability levels of each individual, it would be transformed into a great achievement booster (Pisik 1992; Cavanaugh et al., 2000; Lepine et al., 2005).

As stated earlier, hindrance stress contributed to a high degree of employees work dissatisfaction (Jones, Chonko, Rangarajan, \& Roberts, 2007) and it would manifest itself in an increase in the employees desire to leave the organization (Jones et al., 2007; Mohr \& Puck, 2007; Golbasi, Kelleci, \& Dogan, 2008). These views have been throughly studied by Nadiri \& Tanova (2010), who concluded that job satisfaction had a significant positive relationship with job performance.

Dewettinck \& Buyens (2005) have proved that hindrance stress can affect the quality of services as well as the labors productivity. Other scholars also argued that continuous exposure to stress will reduce the performance of employees in the workplace (Sharpley et al., 1996; Aryee, Zhou, Sun, \& Lo, 2009; O'Neill \& Davis, 2011). When an individual is confronted with a lower 
threshold of stressor in comparison to his or her ability to manage it, then that individual will feel satisfied and happy. This condition is called challenge stress or eustress, which literally means good stress. It is a situation where the stress agent becomes a motivational catalyst and a positive personal development tool for such individuals (Sen, 2008; Cavanhaugh et al., 2000; Lepine et al., 2005; O'Neill \& Davis, 2011). Gill (2008) believed that employees who had a positive outlook, such as a high regard towards their organization, would feel more satisfied in their jobs. This feeling would be manifest in a reduction in the employees' intention to resign from their job. Through high job satisfaction, higher levels of commitment among employees can be generated, thus reducing the turnover rate (AlBattat \& Mat Som, 2013; Günlu et al., 2010; Silverthorne, 2004).

Based on the research above, it is clear that a systematic understanding of the various stress levels is able to help the hotel sector to establish a more effective work enviroment and enhance positive outcomes (Sneed, 1988). Managers should be aware that the creation of more of the challenging stress should be prioritized. This can be achieved through organizational justice. The importance of organizational justice and its impact in the hospitality sector is enormous, because it also affects the quality of service through the employees' performances (Nadiri \& Tanova, 2010).

\section{RESEARCH INSTRUMENT}

Researchers found that the stress instrument that was developed by Cavanaugh et al. (2000), identified as the Challenge and Hindrance Self Reported Stress Related Measures (CHS) was an appropriate instrument for measuring stress. Cavanaugh and his colleagues had developed a stress measurement method that could assess the two types of stress, i.e. challenge stress (eustres) and hindrance stress (distress), as discussed in the previous reviews.

For the purpose of developing the CHS, Cavanaugh et al. (2000) adapted the three existing instruments from the Job Demand and Worker Health (Caplan et al., 1993), Stress
Diagnostic Survey (SDS) (Ivancevich \& Matteson, 1983), and Job Stress Index (JSI) (Sandman, 1992). Cavanaugh et al. (2000) examined each selected item and categorized it according to its appropriate stress type, whether it was a challenge, hindrance or both.

Based on the individual definitions of challenge stress and hindrance stress, Cavanaugh et al., (2000) could identify appropriate items which could be separated into their respective category. As such, Cavanaugh et al. (2000) could identify six (6) items that could be categorized as a challenge stress, five (5) items that could be classified as hindrance stress while the other five (5) items were listed as other stress. Other items that were not related to stress were dropped as the focus of their research was to measure the challenge stress and hindrance stress.

Challenge stresses' indicating factors include demands of work, the workload, time constraints, job accountability and job intricacy. The gauging factor for hindrance stresses include inflexible bureaucracy, imprecise roles, roles and interpersonal conflict, task disturbance and any internal politics of the organization (Cavanaugh et al., 2000; Lepine, et al., 2005).

In a test conducted on 10,000 top-level managers in the United States, the study found that these instruments had a high consistency of $\alpha=0.87$ and $\alpha=0.75$. The stress model loading factor was between 0.60 and 0.87 for each item. This result proved that each item was relevant (Cavanaugh et al., 2000). Among the studies that used CHS was Raja \& Abbas (2012) but this study only used five items from challenge stress and hindrance stress respectively. As a result, the validity of that study was low. A total of 10 items measuring stress-challenge and stresshindrance were used and distributed to 300 respondents and 255 questionnaires were returned and the author found that both types of stress were independent of multicollinearity.

Past studies have found that the two types of stress are different and have different effects on employees' behaviors (Raja \& Abbas, 2012; Lepine et al., 2005; Cavanaugh et al., 2000). Hindrance stress posed a risk while challenge 
stress could expand innovative and creative behavior. Cavanaugh et al. (2000) also found out that challenge stress reacted positively, while hindrance stress responded negatively in relation to job satisfaction.

\section{ANALYSIS RESULT}

Researchers have found that Cavanaugh's (2000) instrument can be applied to the perspective of Asian studies. Through the EFA analysis that had been conducted, it showed that stress was divided into two factors, namely the dimension of challenge stress (CS) and the dimension of hindrance stress (HS) (refer to Table 2). Table 5 also shows that all the items of these two variables are normal. Using AMOS, skewness and kurtosis values of between 2 and -2, as suggested by Tabachnick \& Fidell (2007), are achieved.

Results showed that the fitness indexes were satisfactory and fulfilled the fitness index suggested in the TLI $=0.992$, CFI $=0.929$, RMSEA $=0.039, \mathrm{GFI}=0.990$ and $\mathrm{AGFI}=0.891$.
Table 3. Mean and Standard Deviation Value

Descriptive Statistics

\begin{tabular}{cccc}
\hline Items & Mean & Std. Deviation & Analysis N \\
\hline CS1 & 3.23 & 1.415 & 115 \\
CS2 & 2.31 & 1.119 & 115 \\
CS3 & 2.93 & 1.145 & 115 \\
CS4 & 2.89 & 1.160 & 115 \\
CS5 & 2.98 & 1.214 & 115 \\
CS6 & 2.90 & 1.185 & 115 \\
HS1 & 5.10 & 1.127 & 115 \\
HS2 & 5.24 & 1.121 & 115 \\
HS3 & 5.18 & 1.167 & 115 \\
HS4 & 5.24 & 1.129 & 115 \\
HS5 & 5.10 & 1.068 & 115 \\
\hline
\end{tabular}

This study also showed that the correlation value $=-0.77$. This proved that both stress factors were different (value $<0.80$ ) and negatively related to each other. The value for each loadings factor showed a value that exceeded the minimum specified value $(0.60)$ (Tabachnick \& Fidell, 2007).

Table 1. KMO and Bartlett's Test

\begin{tabular}{llr}
\hline Kaiser-Meyer-Olkin Measure of Sampling Adequacy. & 0.944 \\
\hline Bartlett's Test of Sphericity & Approx. Chi-Square & 1251.815 \\
& df & 55 \\
Sig. & 0.000 \\
\hline
\end{tabular}

Table 2. Total Variance Explained

\begin{tabular}{cccccccc}
\hline & \multicolumn{3}{c}{ Extraction Sums of Squared Loadings } & & \multicolumn{3}{c}{ Rotation Sums of Squared Loadings } \\
\cline { 2 - 3 } Component & Total & \% of Variance & Cumulative \% & & Total & \% of Variance & Cumulative \% \\
\hline 1 & 7.684 & 69.857 & 69.857 & & 4.549 & 41.352 & 41.352 \\
2 & 1.234 & 11.217 & 81.074 & & 4.369 & 39.722 & 81.074 \\
\hline
\end{tabular}

Extraction Method: Principal Component Analysis. 


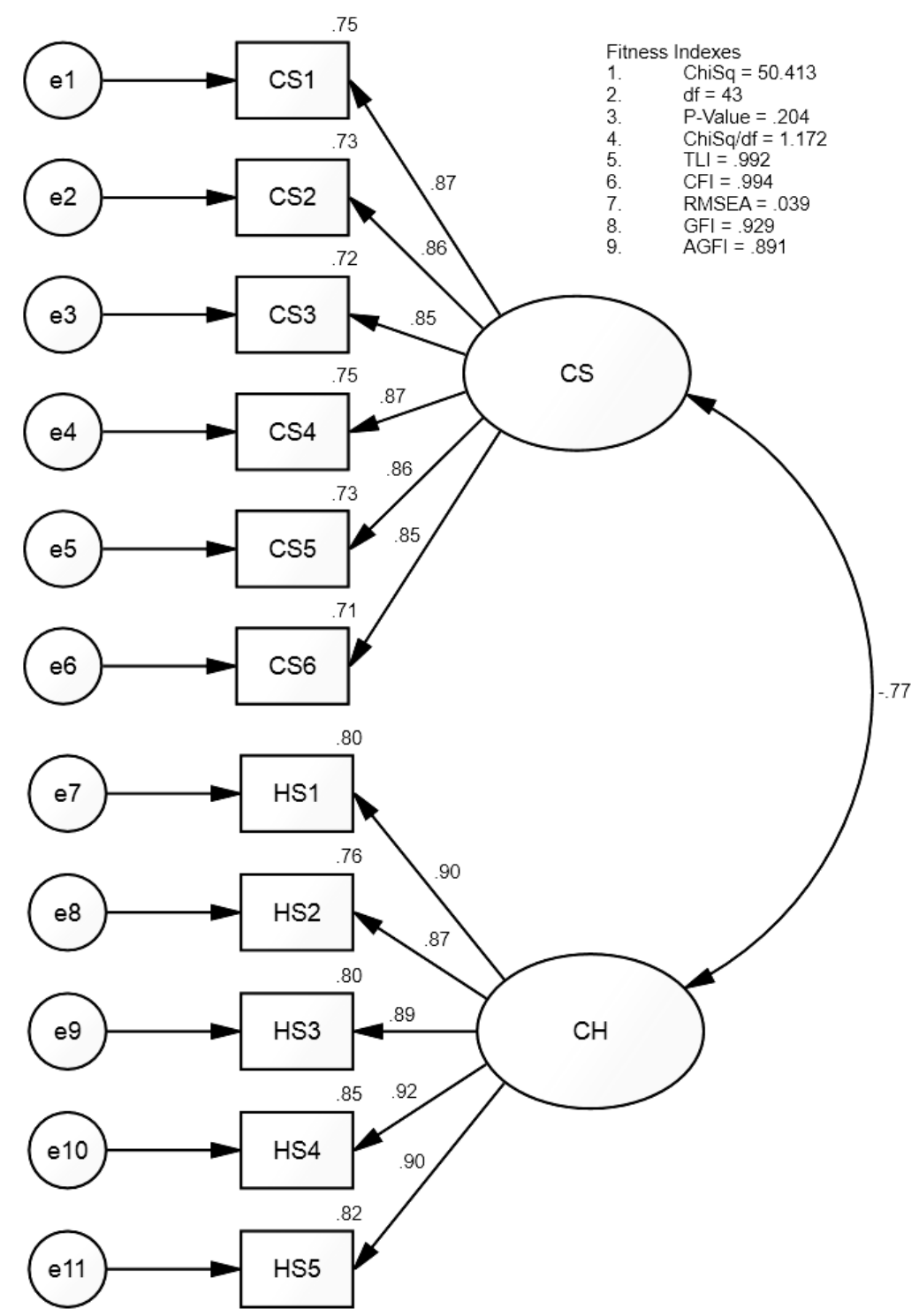

Figure 1. Challenge-stress and Hindrance-stress Overall Model

Table 4. Standard Regression Weights

\begin{tabular}{cccc}
\hline & & & Estimate \\
\hline CS6 & $<---$ & CS & 0.845 \\
CS5 & $<---$ & CS & 0.856 \\
CS4 & $<---$ & CS & 0.866 \\
CS3 & $<---$ & CS & 0.848 \\
CS2 & $<---$ & CS & 0.857 \\
CS1 & $<---$ & CS & 0.866 \\
HS5 & $<---$ & CH & 0.905 \\
HS4 & $<---$ & CH & 0.924 \\
HS3 & $<---$ & CH & 0.893 \\
HS2 & $<---$ & CH & 0.870 \\
HS1 & $<---$ & CH & 0.897 \\
\hline
\end{tabular}


Table 5. Variable Normality

Assessment of normality (Group number 1)

\begin{tabular}{ccccccc}
\hline Variable & Min & $\max$ & skew & c.r. & kurtosis & c.r. \\
\hline HS1 & 2.000 & 7.000 & -0.723 & -3.166 & 0.390 & 0.853 \\
HS2 & 2.000 & 7.000 & -0.678 & -2.966 & 0.366 & 0.801 \\
HS3 & 2.000 & 7.000 & -0.525 & -2.300 & -0.168 & -0.367 \\
HS4 & 1.000 & 7.000 & -0.709 & -3.105 & 0.648 & 1.419 \\
HS5 & 2.000 & 7.000 & -0.539 & -2.358 & -0.165 & -0.361 \\
CS1 & 1.000 & 7.000 & 0.305 & 1.335 & -0.606 & -1.327 \\
CS2 & 1.000 & 6.000 & 0.757 & 3.316 & 0.128 & 0.281 \\
CS3 & 1.000 & 7.000 & 0.383 & 1.676 & 0.253 & 0.555 \\
CS4 & 1.000 & 6.000 & 0.356 & 1.561 & 0.063 & 0.138 \\
CS5 & 1.000 & 6.000 & 0.152 & 0.663 & -0.742 & -1.625 \\
CS6 & 1.000 & 6.000 & 0.281 & 1.230 & -0.445 & -0.973 \\
Multivariate & & & & & 18.093 & 5.737 \\
\hline
\end{tabular}

\section{FINDINGS DISCUSSION}

It has been proven that stress not only can produce a negative situation, but it can also play a role in generating a positive situation in the hospitality industries in Southeast Asia. Viewing Indonesia as a country that shares a similar culture with, and most of the same demografic profile as, the people of this country (Malaysia), then these findings can also reflect similar Indonesian perspectives. Extensive knowledge about the different types of stress is vital and needs to be identified by management in both countries. Said management should be able to determine which type of stress needs to be reduced and which type needs to be introduced in appropriate amounts in order to boost employees' motivation.

The analytical results of this study indicated that there were two dimensions of stress, i.e. challenge stress and hindrance stress. The findings have shown that all items are applicable to the study and every loading factor was above the minimum value of 0.60 which was set. This study supports the findings of Cavanaugh et al. (2000) who authored these instruments. The classification of items for each dimension of stress is also appropriate in the context of the study in Malaysia, which may also reflect the same in the Indonesian hotel sector.
Malaysian hospitality organizations should establish workloads based on the ability of their employees, so that the additional stresses faced by the employees will still be regarded as a challenge. As stated by Kim (2008), workloads are among the factors that trigger stress and lead to service failures. From the Indonesian perspective, reports from there mirror this current study, as workloads are also causing stress (Amin \& Akbar, 2013). Therefore to avoid hindrance stress from occurring, workloads need to be divided equally among employees, based on their ability to handle the load.

Time spent in the organization is also associated with challenge-stress. The longer the time employees spend on improving their performance, the better the skills they will develop. Given that the hospitality industries' employees often have extended working hours, constructive communication channels between the employees and the management must be created. This encourages the employee-management relationship, which will produce more conducive situations for achieving job satisfaction in the workplace (Kusluvan \& Kusluvan, 2000; Kim, Shin, \& Umbreit, 2007).

This study also supports the findings of Cavanaugh and his colleagues, who stated that the scope of responsibility held by the employees in 
the organization was related to the challenge stress. It is significant for the management of organizations that the need to clearly explain the relevant information in relation to the scope of work of an employee is met. These accurate particulars can help the employees to understand their role in carrying out their tasks correctly. This information must be disbursed in a precise and timely manner (Muzumdar, 2012).

Through appropriate explanations and the information provided, employees will understand the scope of their job, and will experience the enjoyment of carrying out the duties and tasks entrusted to them correctly. It must be stressed again that the work-load must also be compatible with the employees' ability. Excessive loads must be supported by other instruments devised by the managers.

Imperatively, the occurrence of red tape or inflexible bureaucracy can slow down the decision-making process. These unproductive processes should be eliminated because they are one of the causes of hindrance-stress. The management should be more focused on making beneficial decisions (Bunja, 2003). Previous research found that organizational politics and favoritism were also types of stressors that formed barriers to workers, undermining their achievements and causing career constraints through hostile working environments (Wan, 2010; Hon et al., 2013).

Limited career development also increases the hindrance-stress in the hospitality sector. The current study supported the findings of Garavan et al. (2006), who found that limited career development undermined the positive form of stress. Lo \& Lamm (2005) also found that high levels of distress in the hotel sector increased turnover rates. The limited career development issues have been blamed on a culture of high voluntary turnover in the hospitality industry in Malaysia as well as in many Southeast Asian countries including Indonesia (Amin \& Akbar, 2013; Asia Management News, 1997 in Khatri, Budhwar, \& Fern, 2000).

\section{RESEARCH IMPLICATIONS}

Through this study, several important implications have been revealed for managements' attention. The management of an organization should be aware that stress can not be categorized only in a negative form, but it can be classified both as positive and negative with separate consequences. The amount of stress which is comparable to the employees' ability must be introduced so that their performance can be at its optimum level. Lack of stress can also weaken workers' performance because there is no challenge in carrying out undemanding work.

Therefore, managers must identify the strengths and weaknesses of their employees to ensure that the level of stress experienced by each employee will always be at the level of challenge stress. Employees' interests must be clearly identified to enable the organization to provide analogous tasks to encourage the employees and to provide challenges to complete their work.

\section{STUDY LIMITATIONS}

The current researcher feels that the duration of this study was too short. Researchers are also having problems in translating the instruments into the local languages. The instruments are not widely used and only a few studies have examined the challenge and hindrance types of stress in detail. Generally, such research concluded that stress was something negative.

Therefore, there is not much support from the previous findings that can be used especially in the perspective of studies in Southeast Asia, such as Malaysia and Indonesia. Due to these predicaments, the current researchers did not thoroughly distinguish the stress generated by individuals but only focussed on the stress generated by organizations.

\section{FUTURE RESEARCH DIRECTIONS}

It is highly recommended that research regarding challenge-stress and hindrance-stress be conducted for the Indonesian perspective. 
Relying on demographic and cultural similarities alone is not enough to make conclusions, drawn from the results of Malaysian studies, which can be applied to Indonesia without proper research using Indonesian respondents. Therefore this current study urges that smilar research be conducted in Indonesia to test the instruments and the results.

Secondly, a continuation of the current study should be considered with the inclusion of a better approach. Among the recommendations for future research are that the period of research should be longer so that a clearer picture of the cause-relationship of stress can be discovered. In addition, future studies should be more focussed on distinguishing the positive and negative stress terminologies, or better known as the challenge and hindrance stresses. These identifications are very important in providing extensive knowledge to the management of organizations for strengthening the positive behavior of employees towards their work. Future researchers should also take into consideration the stress factors caused by individuals alongside the stress factors caused by organizations. Using both the organizations and individuals stress factors will further develop the thorough understanding of the diverse factors that may contribute to stress among the workers.

\section{CONCLUSIONS}

This study is one of the successful studies that contributes new knowledge to the field of management by clarifying the role of stress as one of the factors that provide impetuses and barriers to employees' performance. This study has successfully bridged the existing studies' gaps using instruments that are rarely used, but can be effectively applied in the future in the Malaysian and Indonesian perspectives and generally in Southeast Asian countries.

The management of service oriented organizations should be proactive with their employees' state of affairs and they should also try to widen the employees' positive perceptions of the organization. The managements' direct manipulation of stressors' causes and effects needs to be timely, and strategically induced to the relevant employees so that the utmost quality of service can be delivered indefinitely. Therefore, superb stress management policies are very significant for the betterment of the organizations, due to the fact that weak stress supervision can lead to job dissatisfaction and subsequent failure of the organization to remain in the industry.

\section{REFERENCES}

AlBattat, A. R. S. and A. P. M. Som, 2013. "Employee dissatisfaction and turnover crises in the Malaysian hospitality industry". International Journal of Business and Management, 8 (5), 62-71.

Amin, Z. and K. P. Akbar, 2013. "Analysis of psychological well-being and turnover intentions of hotel employees: An empirical study". International Journal of Innovation and Applied Studies, 3 (3), 662-671.

Aryee, S., Q. Zhou, L. Y. Sun, and S. Lo, 2009. "Perceptions of politics, intrinsic motivation and creative performance: evidence from the service sector". Academy of Management, 5(1), 1-6.

Aziz, Y. A. 2008. "The effects of emotional dissonance and employee's empowerment on service quality and customer satisfaction perception: Customer level analysis”. International Journal of Economics and Management, 2 (3), 237-258.

Blaug, R., A. Kenyon, and R. Lekhi, 2007. "Stress at Work: A report prepared for The Work Foundation' s Principal Partners”. Available at: www.theworkfoundation.com accessed December 10, 2013.

Bunja, D. 2003. "Modernizing the Croatian tourism industry". International Journal of Contemporary Hospitality Management, 15 (2), 126-128.

Caplan, D. R. and R. V. Harrison, 1993. "Person-environment fit theory: Some history, recent developments, and future directions”. Journal of Social Issues, 49 (4), 253275.

Cavanaugh, M. A., W. R. Boswell, M. V. Roehling, and J. W. Boudreau, 2000. "An empirical examination of self-reported work stress among U.S. managers". Journal of Applied Psychology, 85 (1), 65-74. 
Cavanaugh, M. A., W. R. Boswell, M. V. Roehling, and J. W. Boudreau, 1998. "Challenge" and "hindrance" related stress among U.S. managers”. Ithaca, NY: Cornell University, School of Industrial and Labor Relations, Center for Advanced Human Resource Studies.

Cooper, C. L. and S. Cartwright, 1994. "Healthy mind, healthy organization: A proactive approach to occupational stress". New York, 47 (2), 455-472.

Dean, A. M. and A. Rainnie, 2004. “Absenteeism from the frontline: Explaining employee stress and withdrawal in a call centre”. Monash University.

Dewettinck, K. and D. Buyens, 2005. "Role stress among front line employees”. In: L. B. Van, P. Gemmel, and D. R.Van, Services management: An integrated approach, Second Edition. San Francisco: Prentice Hall.

Garavan, T. N., F. O’Brien, D. O’Hanlon, 2006. "Career advancement of hotel managers since graduation: A comparative study”. Personnel Review, 35 (2), 252-280.

Gill, A. S., 2008. “The role of trust in employeemanager relationship”. International Journal of Contemporary Hospitality Management 20 (4), 98-103.

Golbasi, Z., M. Kelleci, and S. Dogan, 2008. "Relationships between coping strategies, individual characteristics and job satisfaction in a sample of hospital nurses: Crosssectional questionnaire survey”. International Journal of Nursing Studies, 45 (1), 1800-1806.

Greenberg, J. (2005). "Managing behavior in organizations”. 4th Edition. New Jersey: Prentice Hall.

Greenglass, E. R., R. J. Burke, and K. A. Moore, 2003. "Reactions to increased workload: Effects on professional efficacy of nurses". Applied Psychology: an International Review, 52 (4), 580-597.

Gunlu, E., M. Aksarayli, and N. S. Perçin, 2010. "Job satisfaction and organizational commitment of hotel managers in Turkey”. International Journal of Contemporary Hospitality Management, 22 (5), 693-717.

Hellriegel, D. and J. W. Slocum, 2007. “Organizational Behavior”. Ohio: Thomson.
Hon, A. H. Y., W. W. H. Chan, and L. Lu, 2013. "Overcoming work-related stress and promoting employee creativity in hotel industry: The role of task feedback from supervisor”. International Journal of Hospitality Management, 33 (1), 416-424.

Hoynala, V. M. 2009. "Effects of unhappy and problematic customers”. Available at: http://publications.theseus.fi/bitstream/handl e/ accessed May 1, 2013

Ivancevich, J. M. 1985. "Predicting absenteeism from prior absence and work Attitudes". Academy of Management Journal, 28 (1), 219-228.

Ivancevich, J.M. and M. T. Matteson, 1983. “Stress Diagnostic Survey”. University of Houston, Houston, Texas.

Jamal, M. and V. V. Baba, 2000. “Job stress and burnout among Canadian managers and nurses: An empirical examination”. Canadian Journal of Public Health, 91 (6), 454460.

Johnson, M., and R. Woods, 2008. “Recognizing the emotional element in service excellence”. Cornell Hotel and Restaurant Administration Quarterly, 49 (3), 310- 316.

Jones, E., L. Chonko, D. Rangarajan, and J. Roberts, 2007. "The role of overload on job attitudes, turnover intentions, and salesperson performance”. Journal of Business Research, 60 (1), 663-671.

Karatepe, O. M., E. Babakus, and U. Yavas, 2012. "Affectivity and organizational politics as antecedents of burnout among frontline hotel employees”. International Journal of Hospitality Management, 31 (2), 66-75.

Karatepe, O. M. and H. Kilic, 2007. "Relationships of supervisor support and conflicts in the work-family interface with the selected job outcomes of frontline employees". Tourism Management, 28 (1), 238-252.

Karatepe, O. M., and A. Sokmen, 2006. "The effects of work role and family role variables on psychological and behavioral outcomes of frontline employees”. Tourism Management, 27 (2), 255-268.

Karatepe, O. M., and O. Uludag, 2008. "Role stress, burnout and their effects on frontline hotel employees' job performance: Evidence from Northern Cyprus”. International 
Journal of Tourism Research, 126 (4), 111126.

Khatri, N., P. Budhwar, and C. T. Fern, 2000. Employee turnover: Bad attitude or poor management?. Retrieved at www.ntu.edu.sg on 23 June 2013.

Kim, H. J. 2008. Hotel service providers' emotional labor: "The antecedents and effects on burnout”. International Journal of Hospitality Management, 27 (1), 151-161.

Kim, H. J., K. H. Shin, and W. T. Umbreit, 2007. "Hotel job burnout: The role of personality characteristics". International Journal of Hospitality Management, 26 (1), 421434.

Kusluvan, S., Z. Kusluvan, Z. Ilhan, and L. Buyruk, 2010. "The human dimension: A review of human resources management issues in the tourism and hospitality industry”. Cornell Hospitality Quarterly, 51 (2), 171-214.

LePine, J. A., N. P. Podsakoff and M. A. LePine, 2005. "A meta-analytic test of the challenge stressor-hindrance stressor framework: An explanation for inconsistent relationships among stressors and performance”. Academy of Management Journal, 48 (5), 76475.

Lo, K. and F. Lamm, 2005. “Occupational stress in the hospitality industry - An employment relations perspective". New Zealand Journal of Employment Relations, 30 (1), 23-47.

Management Services. 2006. “Tackling absenteeism in the workplace". Institute of Management Services, (Autumn), 44-45.

Mohr, A. T., and J. F. Puck, 2007. "Role conflict, general manager job satisfaction and stress and the performance of IJVs". European Management Journal, 2 (1), 25-35.

Mullins, L. J. 2005. "Management and organizational behaviour". 7th Edition. England: Prentice Hall.

Muzumdar, P. 2012. "Influence of interactional justice on the turnover behavioral decision in an organization”. Journal of Behavioral Studies in Business, 5 (1), 1-11.

O’Neill, J. and K. Davis, 2011. "Work stress and well-being in the hotel industry". International of Hospitality Management, 30 (1), 385-390.
Pisik, B. 1992. "Eustress and distress - both good and bad, the pressure is on". The Washington Times.

Poon, J. M. L. 2003. "Situational antecedents and outcomes of organzational politics perception”. Journal of Managerial Psychology, 18 (2), 138-155.

Raja, U., and M. Abbas, 2012. "Differential effects of hindrance and challenge stressors on innovative performance". Available at: http://www.wbiconpro.com/429-Usman.pdf accessed November 22, 2013.

Robbins, S. P. and T. A. Judge, 2007. "Organizational Behavior”. 12 ${ }^{\text {th }}$ Edition. Jersey: Pearson Prentice Hall.

Samad, S. 2011. "Predictors of employee willingness to engage with customer behavior". European Journal of Social Sciences, 22 (4), 611-619.

Sen, S. 2008. "Executives and the stress factor". The ICFAI Journal of Soft Skills, 2 (1), 3944.

Sharpley, C. F., R. Reynolds, A. Acosta, and J. K., Dua, 1996. "The presence, nature and effects of job stress on physical and psychological health at a large Australian University". Journal of Educational Administration, 34 (4), 73-86.

Silverthorne, C. 2004. "The impact of organizational culture and person organization fit on organizational commitment and job satisfaction in Taiwan". The Leadership and Organization Development Journal, 25 (7), 592-599.

Sneed, J. 1988. "Job characteristics and job satisfaction of school foodservice employees”. School Food Service Review, 88 (12), 65-68.

Srikhum, P. 2013. "The study of employees' stress on job performance in five-star hotels in Bangkok". The Clute Institute International Academic Conferences.

Stevens, M. and D. J. Higgins, 2002. "The influence of risk and protective factors on burnout experienced by those who work with maltreated children”. Child Abuse Review, 11 (1), 313-331.

The Jakarta Globe. 2013. "Indonesian Hospitality Sector to Grow in 2014: Realtors". 
Available at: http://thejakartaglobe. beritasatu.com accessed June 29, 2015.

Tuten, T. L., and P. E. Neidermeyer, 2004. "Performance, satisfaction and turnover in call centers: The effects of stress and optimism". Journal of Business Research, 57 (1), 26-34.
Wan, Y. K. P., 2010. "Exploratory assessment of the Macao Casino dealers' job perceptions”. International Journal of Hospitality Management, 29 (2), 62-71.

World Travel and Tourism Council. 2014. "Travel and tourism economic impact 2014 Malaysia”. Available at: http://www.wttc.org//media/files/reports/ June 29, 2015. 